\title{
Subunit-Dependent Postsynaptic Expression of Kainate Receptors on Hippocampal Interneurons in Area CA1
}

\author{
Joyce Wondolowski and Matthew Frerking \\ Department of Behavioral Neuroscience and Neuroscience Graduate Program, Oregon Health \& Science University, Beaverton, Oregon 97006
}

\begin{abstract}
Kainate receptors (KARs) contribute to postsynaptic excitation in only a select subset of neurons. To define the parameters that specify the postsynaptic expression of KARs, we examined the contribution of KARs to EPSCs on hippocampal interneurons in area CA1. Interneurons in stratum radiatum/lacunosum-moleculare express KARs both with and without the GluR5 subunit, but KAR-mediated EPSCs are generated mainly, if not entirely, by GluR5-containing KARs. Extrasynaptic glutamate spillover profoundly recruits AMPA receptors (AMPARs) with little effect on KARs, indicating that KARs are targeted at the synapse more precisely than AMPARs. However, spontaneous EPSCs with a conventional AMPAR component did not have a resolvable contribution of KARs, suggesting that the KARs that contribute to the evoked EPSCs are at a distinct set of synapses. GluR5-containing KARs on interneurons in stratum oriens do not contribute substantially to the EPSC. We conclude that KARs are localized to synapses by cell type-, synapse-, and subunit-selective mechanisms.
\end{abstract}

Key words: kainic acid; hippocampus; interneurons; synaptic; glutamate receptor; glutamate transporters

\section{Introduction}

Glutamate is the major excitatory neurotransmitter in the CNS. There are three main subtypes of ionotropic glutamate receptors: NMDA receptors, AMPA receptors (AMPARs), and kainate receptors (KARs) (Bettler and Mulle, 1995; Lerma et al., 2001; Huettner, 2003). AMPARs and KARs are homologous and have similar biophysical properties in expression systems but play distinct roles in the CNS (Lerma, 2006; Pinheiro and Mulle, 2006). KAR-mediated EPSCs are found at several central synapses (Castillo et al., 1997; Vignes and Collingridge, 1997; Cossart et al., 1998; Frerking et al., 1998; DeVries and Schwartz, 1999; Kidd and Isaac, 1999, 2001; Li et al., 1999; Bureau et al., 2000; Eder et al., 2003), and extrasynaptic somatodendritic KARs regulate cellular excitability (Melyan et al., 2002; Fisahn et al., 2005).

Within the hippocampus, KARs play a variety of roles and are expressed both on excitatory principal neurons and inhibitory interneurons. Interneurons limit circuit excitability, coordinate network oscillations, and mediate release of several neuropeptides (Freund and Buzsaki, 1996; McBain and Fisahn, 2001; Baraban and Tallent, 2004). It has been widely proposed that interneuronal KARs may be a key site at which interneurons can be regulated to affect circuit excitability (Frerking and Nicoll, 2000; Khalilov et al., 2002; Christensen et al., 2004), but the roles of KARs on interneurons remain unclear.

Received 0ct. 5, 2008; revised Nov. 10, 2008; accepted Nov. 20, 2008.

We acknowledge Craig Jahr and Rowland Taylor for insightful discussion, Sean Wolfson and Rachel Dresbeck for assistance with manuscript preparation, and Dara Partovi for technical assistance. M.F. is supported by National Institutes of Health Grants NS045101, MH077120, and AG026051, and J.W. is supported by National Institutes of Health Predoctoral Fellowship NS060655.

Correspondence should be addressed to Dr. Matthew Frerking, Department of Behavioral Neuroscience, Oregon Health \& Sciences University, 505 185th Avenue, Beaverton, OR 97006. E-mail: frerking@ohsu.edu.

DOI:10.1523/JNEUROSCI.4788-08.2009

Copyright $\odot 2009$ Society for Neuroscience $\quad$ 0270-6474/09/290563-12\$15.00/0
KARs are composed of five subunits (GluR5-GluR7, KA1, and KA2) (Huettner, 2003). GluR5 is thought to be of particular importance in interneurons, because these cells express most of the GluR5 in the hippocampus (Bureau et al., 1999; Paternain et al., 2000). KAR-mediated currents can be elicited by GluR5selective agonists (Maingret et al., 2005) and are abolished in mice that lack both the GluR5 and GluR6 subunits (Mulle et al., 2000). These findings suggest that GluR5-containing KARs contribute to interneuronal excitation and activation. However, other studies report that KAR currents are abolished in mice lacking only GluR6 (Fisahn et al., 2004) and are resistant to GluR5 antagonists (Christensen et al., 2004); this suggests that GluR5-containing KARs are excluded from the somatodendritic compartment. One potential complication of using genetic knock-outs to address this issue is that compensation by the remaining receptor subunits may result in mislocalization of these receptors (Christensen et al., 2004).

To better define the role of KARs in the interneuronal EPSC, we used whole-cell patch-clamp recording to directly examine and compare the properties of KARs in two distinct subtypes of interneurons during activation by exogenous agonists and by synaptically released glutamate. We found that most somatodendritic KARs on interneurons in stratum radiatum/lacunosummoleculare (SR/SLM) lack the GluR5 subunit, but postsynaptic KARs on these cells contain GluR5. The localization of GluR5containing KARs at the synapse is highly precise and is distinct from the distribution of AMPARs. These KARs contribute substantially to synaptic charge transfer in SR/SLM interneurons but not stratum oriens ( $\mathrm{SO}$ ) interneurons. These results demonstrate that the localization of KARs at the synapse is regulated by receptor subunit composition, varies across different excitatory synapses onto SR/SLM interneurons, and differs between interneurons in SR/SLM and those in SO. 


\section{Materials and Methods}

Recordings were performed as described by Frerking et al. (1998). Briefly, hippocampal slices $(300-400 \mu \mathrm{m}$ thick) were prepared from 2- to 3-week-old Sprague Dawley rats. Rats were rapidly decapitated under deep anesthesia with the inhalant anesthetic halothane, the brain was removed, and hippocampi were bilaterally dissected out. Hippocampal slices were cut using a Vibratome and incubated for $>1 \mathrm{~h}$ in artificial CSF solution containing the following (in mM): $119 \mathrm{NaCl}, 26.2 \mathrm{NaHCO}_{3}, 11$ glucose, $2.5 \mathrm{KCl}, 4 \mathrm{CaCl}_{2}, 4 \mathrm{MgSO}_{4}$, and $1.0 \mathrm{NaH}_{2} \mathrm{PO}_{4}$ (bubbled with $\left.95 \% \mathrm{O}_{2}-5 \% \mathrm{CO}_{2}\right)$. The slices were kept in a perfusion chamber until the experiment, at which time they were transferred to a recording chamber.

All experiments were done in the presence of $100 \mu \mathrm{M}$ D-APV and 100 $\mu \mathrm{M}$ picrotoxin to block NMDA and $\mathrm{GABA}_{\mathrm{A}}$ receptors, respectively, and $100 \mu \mathrm{M}$ NBQX was applied at the end of experiments to ensure that the measured EPSCs were mediated by AMPAR/KARs. Rapid application of agonists was done with PV830 Pneumatic PicoPump attached to a patch pipette placed near the cell; agonist delivery was driven by brief (10-20 $\mathrm{ms}$ ) application of pressure (5-25 psi) to the pipette. Both pressure and bath application of agonists were performed in the presence of $0.5 \mu \mathrm{M}$ TTX. For pressure-evoked application of agonists, a high concentration of agonist in the pipette was used $(100 \mu \mathrm{M})$, as is generally the case for this type of experiment; the concentration of agonist seen by receptors on the cell is unknown but presumably far smaller as a result of dilution as the agonist diffuses through the tissue. Patch pipettes were filled with internal solution containing the following (in $\mathrm{mm}$ ): $100 \mathrm{CsOH}, 100$ gluconic acid, $2.5 \mathrm{CsCl}, 10$ tetraethylammonium $\mathrm{Cl}, 5 \mathrm{QX}-314 \mathrm{Cl}$ [2(triethylamino)- $\mathrm{N}$-(2,6-dimethylphenyl) acetamine $\mathrm{Cl}$ ], $8 \mathrm{NaCl}, 10$ HEPES, 10 CsBAPTA, $4 \mathrm{Mg}$ ATP, $0.3 \mathrm{Na}_{3} \mathrm{GTP}$, and 0.1 spermine. A high concentration of CsBAPTA was used in the internal solution to block slow $\mathrm{Ca}^{+2}$-gated conductances during the EPSC that might contaminate the measured tail currents.

Area CA3 was microdissected away from area CA1 to prevent recurrent excitation. Schaffer collateral/commissural fibers were stimulated with a bipolar stimulating electrode placed in stratum radiatum, at a rate of $0.1 \mathrm{~Hz}$ between stimuli. Stimuli were delivered either singly or in brief trains of two to five stimuli at $20-100 \mathrm{~Hz}$. Whole-cell voltage-clamp recordings were obtained from CA1 interneurons identified using infrared differential interference microscopy and held at $-70 \mathrm{mV}$. Displaced pyramidal cells outside of stratum pyramidale (SP) were excluded from the analysis by avoiding cells that had a prominent apical dendrite running parallel to that of pyramidal cells. The characteristics of the interneurons we studied here are described extensively in supplemental Note 1 (available at www.jneurosci.org as supplemental material); briefly, we selected interneurons in SR/SLM that are clustered around the border between these two layers, whereas we selected interneurons in SO by choosing cells that were clearly located outside SP, with dendrites running parallel to the alveus (supplemental Fig. 1, available at www. jneurosci.org as supplemental material).

Electrophysiological recordings were obtained using Axopatch amplifiers and IgorPro Software, filtered at $2 \mathrm{kHz}$, and digitized at $10 \mathrm{kHz}$. Series resistances (typically between 10 and $25 \mathrm{M} \Omega$ ) and input resistances (typically between 200 and $500 \mathrm{M} \Omega$ ) were monitored online to ensure stability of recordings. Recordings were excluded from analysis if these parameters changed by $>25 \%$ over the course of the experiment, unless this change was an expected consequence of the experimental protocol (i.e., a change in the input resistance associated with agonist application). Cells were also excluded if the observed result could be explained by an associated change in either parameter, even if the magnitude of the change was $<25 \%$.

Data analysis was performed using IgorPro and SigmaPlot software; spontaneous EPSCs (sEPSCs) were detected and analyzed using MiniAnalysis and Neuromatica. Our threshold for resolution of sEPSCs was routinely $\sim 3-5 \mathrm{pA}$. Spontaneous events were aligned by rise time for averaging. Data were compared using the Student's $t$ test, and paired $t$ tests were used as appropriate. Significance was assessed at $p<0.05$. All data are presented as mean \pm SEM.

\section{Results \\ GluR5-containing KARs are a minor contributor to agonist- evoked KAR currents}

To define the somatodendritic population of KARs, we examined agonist-induced currents on SR/SLM interneurons. These interneurons have been shown in previous studies to express the poreforming subunits GluR5 and GluR6 and the accessory subunit KA2 (Bureau et al., 1999; Lein et al., 2007) (supplemental Note 1, available at www.jneurosci.org as supplemental material). Changes in the holding current were measured in response to bath application of kainate receptor agonists and antagonists, with an extracellular solution containing D-APV $(100 \mu \mathrm{M})$, picrotoxin $(100 \mu \mathrm{M})$, and GYKI 53655 [1-(4-aminophenyl)-3methylcarbamyl-4-methyl7,8-methylenedioxy-3,4-dihydro- $5 \mathrm{H}$ 2,3-benzodiazepine] $(100 \mu \mathrm{M})$ to block NMDA, GABA $\mathrm{A}$, and AMPA receptors, respectively. To activate interneuronal KARs without respect to their subunit composition, we used the nonselective agonists kainate and domoate (for a summary of relevant pharmacology, see supplemental Note 2 and Table 1, available at www.jneurosci.org as supplemental material). Low doses of domoate $(50 \mathrm{nM})$ and kainate $(3 \mu \mathrm{M})$ elicited average inward currents of $103 \pm 26 \mathrm{pA}(n=5)$ and $81 \pm 14 \mathrm{pA}(n=7)$ (supplemental Fig. 2, available at www.jneurosci.org as supplemental material), respectively, that were subsequently blocked with NBQX $(100 \mu \mathrm{M})$, a nonselective AMPAR/KAR antagonist.

To assess the contribution of GluR5-containing KARs to agonist-evoked currents, we used the GluR5-selective antagonist UBP 302 [( S)-1-(2-amino-2-carboxyethyl)-3-(2-carboxybenzyl)pyrimidine-2,4-dione] $(10 \mu \mathrm{M})$. We first established that this antagonist was selective for KARs, because it did not block currents induced by bath-applied AMPA (100 nM plus $100 \mu \mathrm{M}$ cyclothiazide in the absence of GYKI 53655) ( $2 \pm 2 \%$ block; $n=$ 6) (Fig. $1 A, D$ ); we then examined whether UBP 302 blocked the currents evoked by kainate and domoate. UBP 302 had a modest effect on the domoate ( $15 \pm 9 \%$ block; $n=5)$ and kainate $(21 \pm$ $9 \% ; n=7$ ) currents (Fig. $1 B, D$ ), which indicates that these currents are mediated mainly by kainate receptors that lack GluR5. However, this does not exclude the possibility that KARs containing GluR5 are present in small numbers that are overwhelmed by a larger population of KARs lacking GluR5. To address this possibility, we bath applied the KAR agonist (RS)-2- $\alpha$-amino-3-(3hydroxy-5-tert-butylisoxazol-4-yl) propanoic acid (ATPA) (3 $\mu \mathrm{M}$ ), which selectively activates GluR5-containing KARs at concentrations $<10 \mu \mathrm{M}$ (Paternain et al., 2000; Alt et al., 2004). ATPA elicited KAR currents (126 $\pm 42 \mathrm{pA} ; n=5)$, and these currents were almost completely blocked by UBP 302 (91 $\pm 4 \%$ block; $n=5$ ) (Fig. $1 C, D$ ). Thus, KARs containing GluR5 are indeed present on these cells and can be recruited by exogenous agonists. Thus, although GluR5-containing KARs were present and could be selectively engaged by a low concentration of ATPA, the majority of the KAR current was mediated by GluR5-lacking KARs when this current was elicited by the nonselective KAR agonists domoate and kainate.

To ensure that our conclusions were not confounded by steady-state activation of the receptors during the prolonged bath application of agonists, we repeated a subset of these experiments with rapid pressure ejection of kainate (Fig. $1 E$ ). Rapid application $(10-20 \mathrm{~ms})$ of kainate $(100 \mu \mathrm{M})$ elicited average inward currents of $29 \pm 7 \mathrm{pA}(n=5)$ that was only modestly blocked $(31 \pm 6 \% ; n=5)$ by UBP 302 . There was no significant difference in effectiveness of UBP 302 whether the agonist was delivered by 

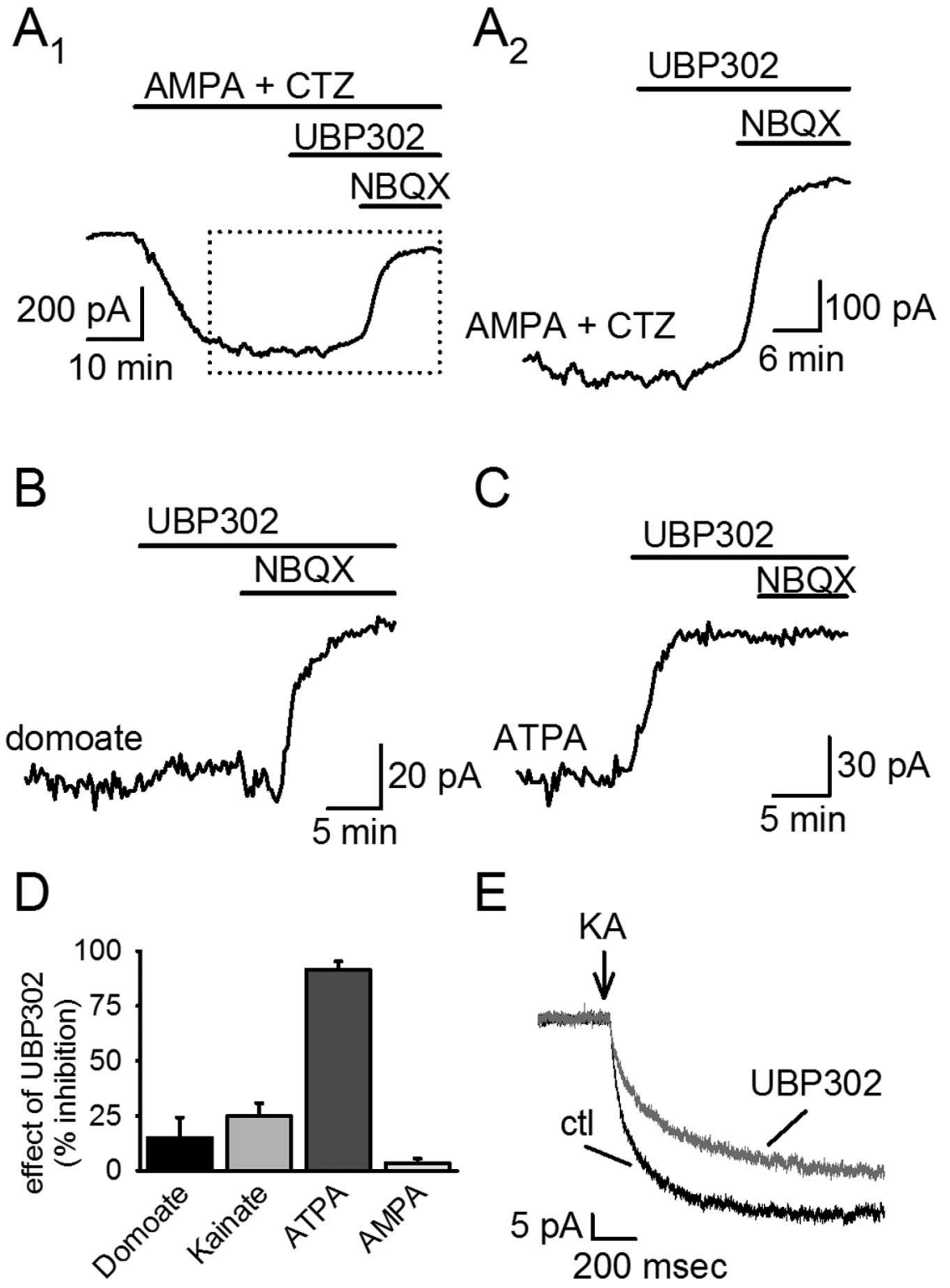

Figure 1. GluR5 is present in a subset of interneuronal kainate receptors. Effects of UBP 302 on agonist-induced currents were examined. UBP 302 had no effect on AMPA-induced currents shown over the entire application of AMPA $\left(A_{1}\right)$ and at higher temporal resolution around the antagonist application $\left(\boldsymbol{A}_{2}\right) \cdot \boldsymbol{B}$, The nonselective KAR agonist domoate induced an inward current that was primarily insensitive to the GluR5-selective antagonist UBP 302. C, ATPA, an agonist that selectively activates GluR5containing KARs, evoked an inward current that was completely blocked by UBP 302. D, A summary of the effect of UBP 302 on various agonist-induced currents. $\boldsymbol{E}$, Effects of UBP 302 on agonist-induced currents were also examined using rapid application methods. A brief puff ( $10-20 \mathrm{~ms}$ ) of $100 \mu \mathrm{m}$ kainate was applied to the cell and induced an inward current in the absence (black) and presence (gray) of UBP 302. CTZ, Cyclothiazide; ctl, control.

bath application or pressure ejection $(p>0.4)$, so the data have been pooled from the two conditions (Fig. 1D).

\section{GluR5-containing KARs are the major receptor subtype underlying the KAR EPSC in SR/SLM interneurons}

Agonist application activates all of the KARs on the cell, precluding differentiation between postsynaptic and extrasynaptic receptors. To determine whether the KARs activated through agonist application were representative of the receptor population activated during synaptic transmission, we examined the effects of UBP 302 on stimulus-evoked EPSCs (eEPSCs) recorded from SR/SLM interneurons. Dual KAR/AMPAR-mediated EPSCs recorded from these cells are biphasic, with a large peak amplitude that decays rapidly and a small tail component that decays slowly. We found previously that addition of GYKI 53655 blocked almost all of the fast peak of the biphasic EPSC; in contrast, the slow tail of the EPSC was primarily, although not entirely, resistant to GYKI 53655 (Frerking et al., 1998).

To examine the effects of UBP 302 on these components of the EPSC, synaptic responses were elicited by extracellular stimulation in stratum radiatum, using either single stimuli or a brief train of five stimuli for better resolution of the small tail current. On average, UBP 302 blocked the peak of the eEPSC by $9 \pm 2 \%$ and the slowly decaying tail of the eEPSC by $40 \pm$ $5 \%(n=9)$ (Fig. 2A, B).

The observation that the tail current was only partially blocked by UBP 302 suggests that only a fraction of the receptors generating the tail current contain GluR5. We thought it likely that the UBP 302insensitive tail current was mediated by KARs that lack GluR5, because these KARs generate the majority of the currents seen during domoate and kainate application. However, because AMPARs were not blocked in this experiment, it remained possible that this remaining tail current was mediated by AMPARs. To differentiate between these possibilities, we recorded pharmacologically isolated KAR eEPSCs in the presence of $50 \mu \mathrm{M}$ GYKI 53655. Surprisingly, UBP 302 blocked the KAR eEPSC in the presence of GYKI 53655 almost entirely (peak, $79 \pm 7 \%$ block; tail, $79 \pm 10 \%$ block; $n=8$ ) (Fig. $2 C, D$ ); in fact, the fractional inhibition of UBP 302 on the KAR EPSC was not significantly different from the fractional inhibition of UBP 302 on currents elicited by the GluR5-selective agonist ATPA.

These results suggested that KARs at the synapse are composed mainly, if not entirely, of GluR5-containing KARs, with the concomitant conclusion that the UBP 302-insensitive tail current of the EPSC is in fact mediated by AMPARs. However, one potential concern with this interpretation is that a recent report has suggested that GluR7-containing KARs may be substantially blocked by GYKI 53655 at concentrations $>10 \mu \mathrm{M}$ (Perrais et al., 2008). In contrast to GluR5 and GluR6, GluR7 expression is minimal in SR/SLM interneurons (supplemental Note 1, available at www. jneurosci.org as supplemental material), so we think it unlikely that GluR7-containing KARs are a significant factor in these cells; however, to ensure that the UBP 302-insensitive component of the EPSC is not mediated by GluR7-containing KARs, we examined the effects of $2 \mu \mathrm{M}$ GYKI 53655 on the EPSC in the presence of UBP 302. This dose of GYKI 53655 is similar to the published IC $_{50}$ of GYKI 53655 for AMPARs $(1-2 \mu \mathrm{M})$ but is well below the $\mathrm{IC}_{50}$ for GluR7-containing KARs $(30-60 \mu \mathrm{M})$ (Perrais et al., 2008). We found that $2 \mu \mathrm{M}$ GYKI 53655 blocked the UBP 302- 
insensitive EPSC by $67 \pm 5 \%(n=6)$ (Fig. $2 E)$, consistent with the inhibition expected if AMPARs mediate the overwhelming majority of the UBP 302insensitive EPSC. Importantly, this low dose of GYKI 53655 blocked the peak and tail of the UBP 302-insensitive EPSC equally and had no effect on the time course of the eEPSC (Fig. $2 E, F)(p>0.3)$; this rules out the idea that the slow component of the UBP 302-insensitive EPSC is selectively mediated by GluR7-containing KARs.

Thus, GluR5-containing KARs are preferentially targeted to the synapse. In contrast, GluR5-lacking KARs are primarily if not entirely excluded from the synapse, although they are the major contributor to KAR currents elicited by domoate and kainate.

\section{Glutamate spillover preferentially recruits AMPARs compared with KARs} The small amplitude and slow kinetics of the KAR EPSC seen here has also been reported at several other synapses (Castillo et al., 1997; Vignes and Collingridge, 1997; Bureau et al., 2000; Kidd and Isaac, 2001). However, KARs at other synapses (DeVries, 2000; Cossart et al., 2002; DeVries et al., 2006) and those that are heterologously expressed (Paternain et al., 1998; Swanson and Heinemann, 1998; Lerma et al., 2001) have large peak amplitudes and rapidly desensitize, similar to the kinetics of AMPARs. The mechanisms underlying these striking differences in the kinetics of the EPSC remain essentially unknown; one possibility with some experimental support is that the kinetics of KARs may be slowed by the expression of the KA1 and KA2 subunits (Contractor et al., 2003; Barberis et al., 2008). Our finding that SR/SLM interneurons express not only a slow KAR EPSC but also a similarly slow AMPAR-mediated tail current caused us to carefully consider the possibility that both of these slow EPSCs are attributable to the simultaneous detection of glutamate spillover by both receptor subtypes at extrasynaptic locations.

As an initial test of this idea, we examined the effects of brief stimulus trains on the tail current relative to the peak current, being careful to examine both the KAR- and AMPAR-mediated tail currents. If glutamate accesses extrasynaptic KARs and AMPARs through spillover out of the cleft, then the successive release events during a brief stimulus train might be expected to more effectively overwhelm uptake and lead to extrasynaptic accumulation of spillover, thereby disproportionately enhancing the slow tail currents.

We compared responses to single stimuli with those elicited by a high-frequency train of five stimuli (Fig. 3). Because of the slow decay kinetics of these EPSCs, each successive stimulus during
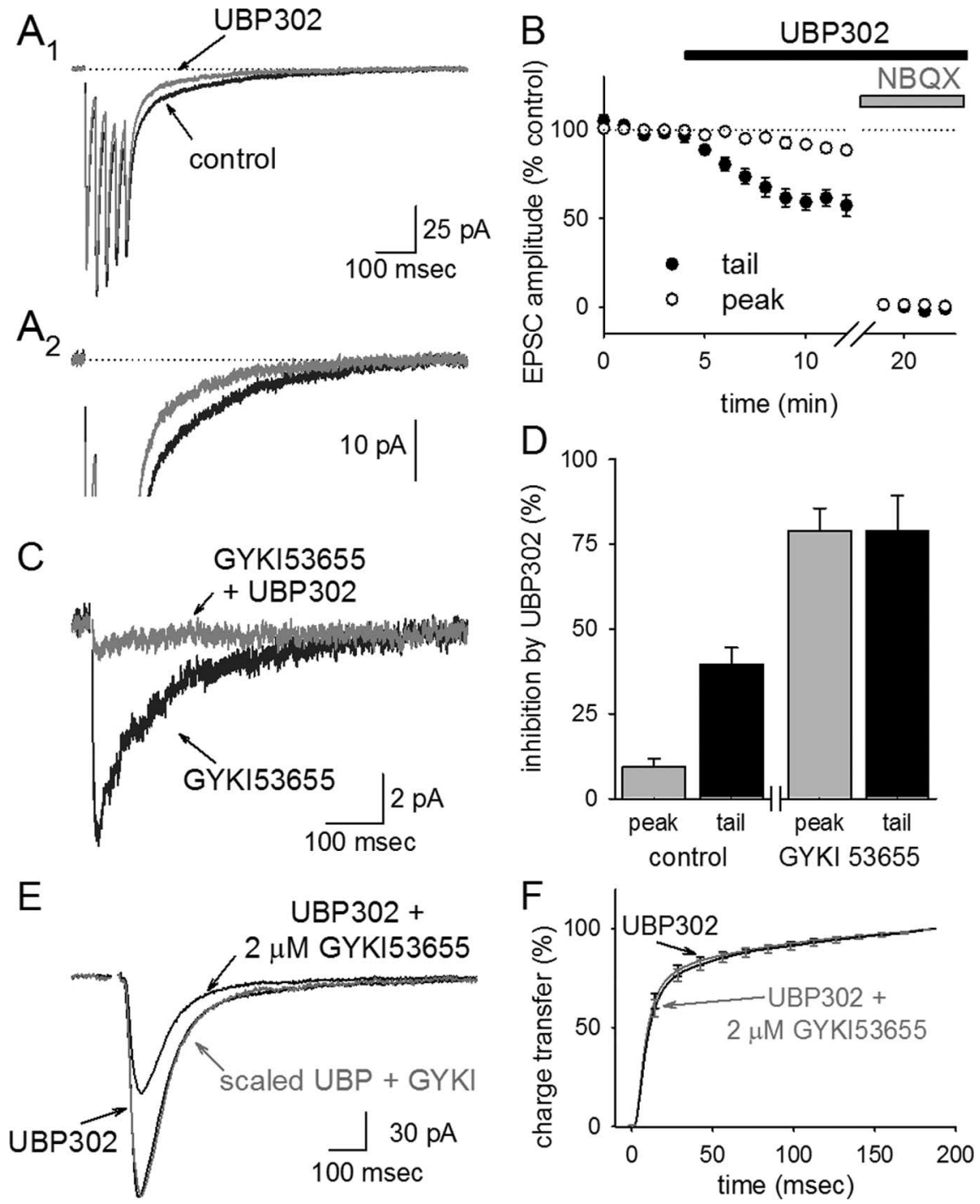

Figure 2. GluR5-containing KARs are selectively activated in response to synaptic glutamate. $\boldsymbol{A}$, EPSCs elicited by a brief train of five stimuli were recorded from an SR/SLM interneuron, as shown at a low $\left(\boldsymbol{A}_{7}\right)$ and a high $\left(\boldsymbol{A}_{2}\right)$ gain. Traces were averaged from 5 to 25 sweeps in control conditions and again after bath application of $10 \mu \mathrm{M}$ UBP 302 . Here and throughout the figures, averaged of the EPSC is primarily unaffected by UBP 302 , and the late, slow component of the tail is significantly, but incompletely, blocked by UBP 302. C, The averaged KAR-mediated EPSC recorded in the presence of GYKI 53655 is almost completely blocked by UBP 302. 302-insensitive component of the eEPSCs (recorded in the presence of $10 \mu \mathrm{m}$ UBP 302) was partially blocked by $2 \mu \mathrm{m}$ GYKI 53655. The kinetics of the partially blocked eEPSC were no different from that of the unblocked eEPSC, as shown by scaling the trace in 2 observed in six cells, as displayed by a comparison of the cumulative charge transfer of the averaged EPSCs in both conditions. Cumulative charge transfers under each condition were normalized to their own maximum value, to facilitate a direct comparison of the kinetics of the EPSCs in each condition. the train occurs before the current returns to baseline, and there is summation of the tail current. To determine whether this summation can be explained by linear summation of the EPSC in response to individual stimuli, we scaled and summated the eEPSC in response to single stimuli and compared this with the eEPSC in response to the stimulus train. The tail current in response to high-frequency stimulation was not disproportionately larger than that expected based on the summation of EPSCs in response to individual stimuli (Fig. 3A). UBP 302 blocked an identical proportion of the charge transfer of the single pulse and train of five eEPSCs (Fig. 3B), indicating that the KAR to AMPAR ratio remains unchanged in response to high-frequency stimula- 
$\mathrm{A}_{1}$

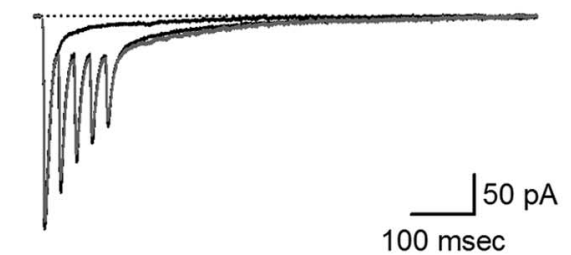

B

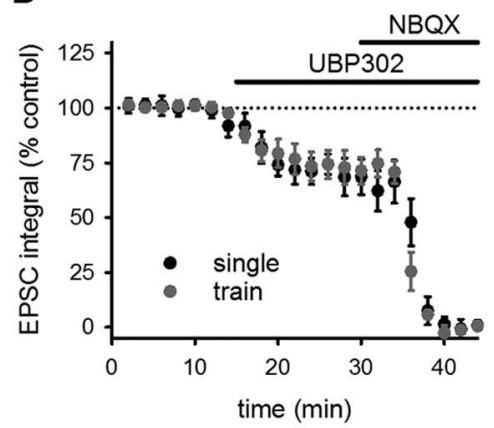

$\mathrm{A}_{2}$

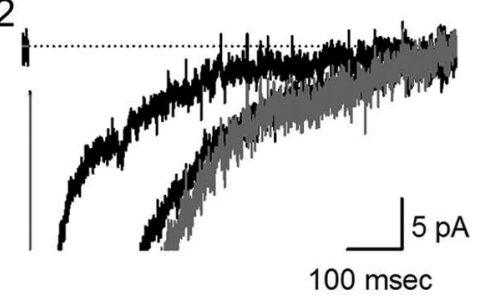

4). The dual KAR/AMPAR-mediated eEPSC showed a dramatic and selective potentiation of the slow tail component in the presence of the TBOA (Fig. $4 A, C$ ), indicating that the inhibition of glutamate uptake could lead to substantial recruitment of AMPARs/KARs attributable to glutamate spillover. The increase in synaptic charge transfer during TBOA application was profound $(910 \pm 146 \%$ charge transfer in TBOA relative to baseline; $n=$ 11) (Fig. 4A,E). However, UBP 302 had a very modest effect on this potentiated tail current, arguing that GluR5-containing KARs were not substantially recruited by TBOA ( $8 \pm 6 \%$ block; $n=10)$ (Fig. $4 B, D)$. The tail current elicited by TBOA could be attributable to extrasynaptic AMPARs or GluR5-lacking KARs that are not accessed by synaptic glutamate release when uptake is intact. To block AMPARs and examine the effects of spillover on KARs in isolation, we repeated these experiments in $50 \mu \mathrm{M}$ GYKI 53655. The KAR eEPSC recorded under these conditions showed no significant enhancement in response to TBOA application (104 $\pm 21 \%$ charge transfer in TBOA relative to control; $n=6$ ) (Fig. 4C,E). Individual cells sometimes showed a modest effect of

tion. Thus, KAR tail currents during the EPSC are not selectively affected by high-frequency activity.

One possible complication in interpreting the amount of block produced by UBP 302 on single versus high-frequency eEPSCs is that the high-frequency train might activate presynaptic KARs in addition to postsynaptic KARs, as has been shown to occur in a subset of somatostatin-containing interneurons (Sun and Dobrunz, 2006). A block of presynaptic KARs could conceivably affect $P_{\mathrm{r}}$ during the train, which would alter short-term plasticity and complicate a comparison of the train-evoked EPSCs with those evoked by single stimuli. However, application of UBP 302 had no effect on short-term plasticity during the train, as assessed by measuring the ratio of peak amplitudes during the fifth and first stimuli (the $\mathrm{p}_{5} / \mathrm{p}_{1}$ ratio) (Fig. $3 C$ ). This argues against an effect of UBP 302 on $P_{\mathrm{r}}$.

The UBP 302-insensitive tail also showed no significant increase in response to a train of stimuli. This suggests that neither the AMPAR tail currents nor the KAR tail currents during these brief trains are attributable to spillover, although we cannot exclude the possibility that the increased glutamate release during a brief train is not sufficient to elicit a resolvable change in spillover relative to a single stimulus. We also note that this result is difficult to reconcile with preferential saturation of KARs. The frequency-dependent depression at these synapses implies a high initial release probability, so the train is likely to evoke repetitive activation of the same synapses. If KARs but not AMPARs were saturated by glutamate, then AMPARs would be able to respond during repetitive activation but KARs would not. This would lead to an increase in the AMPAR contribution to the charge transfer during trains relative to single stimuli, which we did not observe.

To more robustly manipulate glutamate spillover, we evoked EPSCs in the presence of DL-threo- $\beta$-benzyloxyaspartic acid (TBOA) $(100 \mu \mathrm{M})$, an inhibitor of glutamate transporters (Fig.

TBOA on the KAR eEPSC as shown in Figure $4 C$, but this was variable across cells, not apparent in the population average, and negligible compared with the effect on the combined AMPAR/ KAR EPSC. The tail current elicited by TBOA was completely blocked by UBP 302 and GYKI 53655 in combination ( $100 \pm 2 \%$ inhibition; $n=4$ ) (Fig. $4 D$ ), and the effects of TBOA were not associated with a significant change in the holding current $(n=$ 10) (Fig. $4 F$ ). We note that the complete blockade of the TBOAinduced currents by UBP 302 and GYKI 53655 makes it highly unlikely that a substantial fraction of this current is mediated by GluR7-containing receptors, which would be expected to have residual currents of $\sim 20-50 \%$ at the dose of GYKI 53655 that we have used $(50 \mu \mathrm{M})$; given that the TBOA-induced increase in charge transfer was often on the order of $1000 \%$ of control values, we would have been able to easily detect residual currents of this magnitude.

Thus, TBOA can lead to a large and slow tail current, indicating that it is effective in eliciting glutamate spillover. However, the tail current recruited by this spillover is overwhelmingly mediated by AMPARs and not KARs, indicating that KARs are localized at the synapse more precisely than AMPARs.

Fast sEPSCs on SR/SLM interneurons are mediated mainly, if not entirely, by AMPARs

Our results thus far show that KARs are not recruited by glutamate spillover, even when spillover is substantially enhanced by blocking glutamate uptake. Thus, KARs appear to be located directly at the synapse. However, it remains possible that KARs are not colocalized at the same synapses that express AMPARs, because evoked EPSCs are generated by the synchronous activation of multiple presynaptic fibers. We therefore examined sEPSCs, which are not subject to this limitation.

Colocalization of AMPARs and KARs should lead to biphasic 
sEPSCs, with an AMPAR-mediated peak, and a tail mediated by KARs and AMPARs. We would not necessarily expect to resolve the tail currents of individual sEPSCs, which would be very small in the presence of substantial baseline noise, but the signal-to-noise resolution can be improved by several-fold by averaging together many sEPSCs $(>50)$ and examining the kinetics of the averaged sEPSC (supplemental Fig. $3 A-C$, available at www.jneurosci.org as supplemental material). A slow tail current was not discernable in the average sEPSCs, nor was there a significant residual transfer of charge 100 $\mathrm{ms}$ after the peak of the sEPSC. There was also no effect of UBP 302 on the sEPSC during the region in which a tail might be expected $100 \mathrm{~ms}$ after the peak $(n=10)$ (Fig. 5A,B).

To ensure that the absence of a tail current in the sEPSC was not being artificially depressed by $4 \mathrm{~mm} \mathrm{Ca} / 4 \mathrm{~mm} \mathrm{Mg}$ external solution used in these experiments, we repeated these experiments in another set of cells with $2.5 \mathrm{~mm} \mathrm{Ca} / 1.3 \mathrm{~mm} \mathrm{Mg}(n=9)$. We observed identical results in both cases (supplemental Fig. 3D, available at www. jneurosci.org as supplemental material) and therefore pooled the data together.

To assess our limits of resolution for the kinetics of the averaged sEPSCs, we examined the cumulative charge transfer over the course of the averaged sEPSC and compared it with the cumulative charge transfer during the eEPSC. The charge transfer during averaged sEPSCs was obviously complete in a much shorter period of time than eEPSCs $(p<0.001)$ (Fig. $5 B)$. The residual charge transfer $100 \mathrm{~ms}$ after the eEPSC onset was $24 \pm 4 \%(n=10)$, whereas the residual charge transfer $100 \mathrm{~ms}$ after the sEPSC onset was negligible $(-1 \pm 2 \% ; n=19)$. Of course, not all of the tail of the eEPSC is mediated by KARs. Given the $40 \pm 5 \%$ inhibition of the tail by UBP 302, we calculate that the residual KAR-mediated charge transfer $100 \mathrm{~ms}$ after the onset of the eEPSC is $10 \pm 2 \%$; this is still clearly much larger that the entire charge transfer during a comparable time window after the sEPSC $(p<0.002)$. Thus, the KARs activated during the eEPSC cannot be explained by KAR colocalization with AMPARs at the synapses that generate conventional AMPAR sEPSCs.

This led us to the prediction that there should be a separate population of synapses with a commensurately smaller contribution of AMPARs but a commensurately larger contribution of KARs. However, we would not necessarily expect to be able to resolve sEPSCs from these synapses, because the peak amplitude of the KAR eEPSC relative to the AMPAR eEPSCs (Fig. 2) would predict an average KAR sEPSC with $<1 \mathrm{pA}$ peak amplitude and very slow kinetics. This is well below our limit of resolution for individual sEPSCs and contrasts markedly with previous reports (Cossart et al., 2002; Goldin et al., 2007), which have found that KARs on interneurons in SO generate sEPSCs and even miniature EPSCs that are large, rapid, and readily detectable (see below); the spontaneous KAR EPSCs observed in these previous reports are similar to AMPAR-mediated currents but persist when AMPARs are blocked. To see whether we could similarly resolve large and fast KAR sEPSCs in SR/SLM interneurons, we first examined whether UBP 302 had any effect on the frequency or peak amplitude of sEPSCs. We were unable to detect an effect of UBP 302 on either parameter (amplitude, $6 \pm 9 \%$ inhibition; frequency, $8 \pm 11 \%$ inhibition; $n=10$ ) (Fig. $5 C$ ). We next examined the effects of GYKI 53655 on sEPSCs recorded from SR/ SLM interneurons to see whether we could resolve any events that were resistant to GYKI 53655. Addition of $50 \mu \mathrm{M}$ GYKI 53655 blocked all detectable events $(n=7)$ (Fig. $5 C, D)$, consistent with our initial expectations based on observations of the eEPSC. These results indicate that the KARs activated during the evoked EPSC in these cells cannot be accounted for by a colocalization of AMPARs and KARs at the synapses that generate rapid sEPSCs.

\section{The KAR EPSC is not explained by multivesicular release}

Although we did not observe a KAR-mediated tail in sEPSCs, one final possibility regarding the colocalization of these receptors with AMPARs is that the KARs are located perisynaptically in an annulus surrounding a synapse containing AMPARs. In this scenario, the KARs would be located at a distance at which they can be engaged by multivesicular release but not univesicular release. This might lead to a selective activation of KARs during stimulusevoked transmission but not spontaneous transmission because multivesicular release requires the high $P_{\mathrm{r}}$ that occurs during the calcium transient elicited by a presynaptic spike but not during spontaneous vesicle fusion (Tong and Jahr, 1994; Christie and Jahr, 2006). 
A

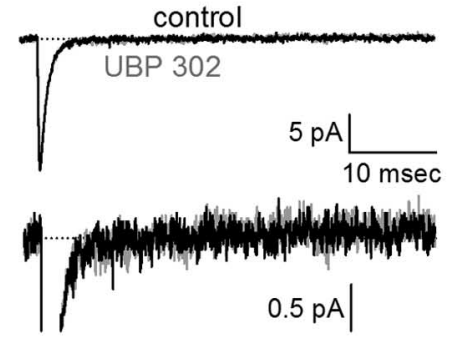

C

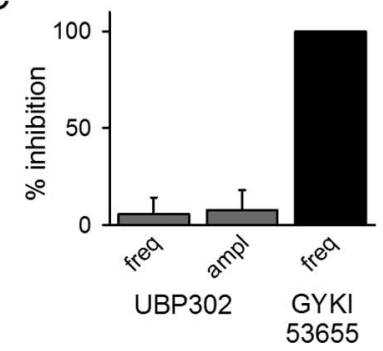

B

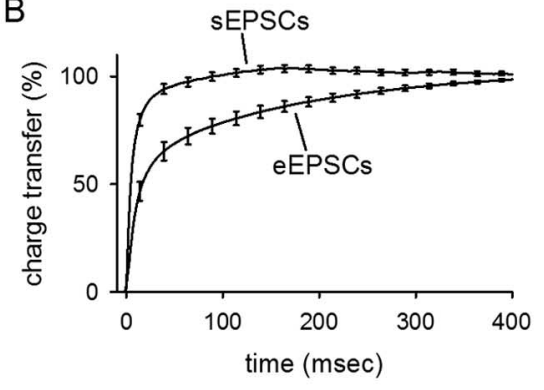

D

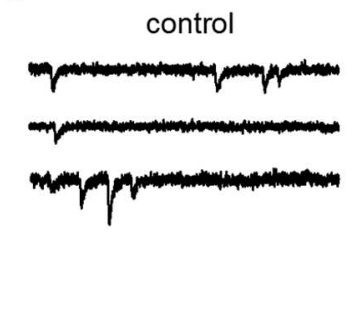

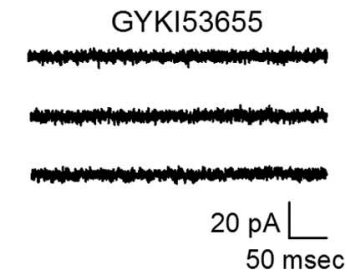

Figure 5. Synapses that generate fast AMPAR sEPSCs cannot account for the tail current of the evoked EPSC. Spontaneous EPSCs were recorded in the presence of picrotoxin and D-APV. A, Averaged sEPSCs were recorded in control conditions (black) and in the presence of UBP 302 (gray). $\boldsymbol{B}$, The cumulative charge transfer of sEPSCs reaches its maximum in $<100$ ms, in contrast to that of the evoked EPSC. C, UBP 302 had no effect on the frequency (freq) or amplitude (ampl) of sEPSCs recorded in control conditions. The sEPSCs were completely blocked by GYKI 53655, indicating that these events were mediated solely by AMPARs. $\boldsymbol{D}$, GYKI 53655 blocked all resolvable sEPSCs, as shown in a representative cell.

If this scenario is correct, then multivesicular release should occur at high $P_{\mathrm{r}}$ and lead to a higher concentration of glutamate in the synaptic cleft. Thus, we can test whether multivesicular release occurs at excitatory synapses onto interneurons by examining whether the concentration of glutamate in the synaptic cleft is sensitive to $P_{\mathrm{r}}$, using low-affinity competitive antagonists to assess glutamate concentration. Briefly, low-affinity competitive antagonists are sensitive to the concentration of synaptically released glutamate because they unbind from the receptor so rapidly that glutamate has a chance to compete with the antagonist for the ligand binding site. If multivesicular release occurs, we would expect that a low-affinity competitive antagonist should be less effective during high $P_{\mathrm{r}}$, at which multivesicular release is dominant, and more effective at low $P_{\mathrm{r}}$, at which univesicular release is dominant.

To test this hypothesis, we examined the inhibition of the eEPSC caused by the low-affinity AMPAR/KAR antagonist $\gamma$-Dglutamylglycine $(\gamma$-DGG) $(500 \mu \mathrm{M})$. In control conditions, $\gamma$-DGG blocked the peak amplitude of the eEPSC by $40 \pm 2 \%$ $(n=10)$ (Fig. $6 A-C)$. We then bath applied the $\mathrm{GABA}_{\mathrm{B}} \mathrm{R}$ agonist baclofen $(5 \mu \mathrm{M})$ to engage presynaptic inhibition and lower $P_{\mathrm{r}}$ and reapplied $\gamma$-DGG. Baclofen reduced the size of the EPSC by $57 \pm 6 \%(n=10)$ (Fig. $6 A, B)$; in the presence of baclofen, $\gamma$-DGG was not significantly more effective than in control conditions ( $41 \pm 3 \% ; n=10$ ) (Fig. 6C). Thus, multivesicular release does not occur at these synapses, precluding a model in which perisynaptic KARs are selectively recruited during evoked transmission but not spontaneous transmission.

\section{KARs do not substantially contribute to the EPSC on SO interneurons}

Our observations of SR/SLM interneurons contrast markedly with previous studies of $\mathrm{SO}$ interneurons, which found that KARs produce clearly resolvable spontaneous synaptic currents in these cells. In these previous studies, even miniature KARs in SO interneurons were found to be large (averaging $\sim 10 \mathrm{pA}$ ), fast (decay

time constant $\sim 10 \mathrm{~ms})$, and frequent $(\sim 2$ $\mathrm{Hz}$ ); these KAR-mediated events were a sizeable fraction of the total population of spontaneous synaptic currents observed (>30\% under a wide range of conditions and across all identified subsets of $\mathrm{SO}$ interneurons) (Cossart et al., 2002; Goldin et al., 2007). Interneurons are heterogeneous, so one possible resolution to these conflicting results is that the properties of KARs in SR/SLM interneurons and SO interneurons differ so that the KAR EPSC in $\mathrm{SR} / \mathrm{SLM}$ interneurons is small and slow, whereas the KAR EPSC in SO interneurons is large and fast.

To test this idea, we recorded eEPSCs from SO interneurons. The slowly decaying tail current was much less robust in $\mathrm{SO}$ interneurons than in SR/SLM interneurons (Fig. $7 A, B$ ); in most $\mathrm{SO}$ interneurons, there was no detectable tail current at all. The difference in the average magnitude of the tail current between interneurons in SO and those in SR/SLM was clearly evident in averaged charge transfer traces in response to brief stimulus trains (SO, $n=11$; SR/SLM, $n=9$ ) (Fig. 7C). SO interneurons can be divided into subpopulations with distinct physiological characteristics (Freund and Buzsaki, 1996; Pouille and Scanziani, 2004); cells with physiological features typical of a common subtype, the O-LM interneuron, were readily identified and accounted for more than half of the SO interneurons recorded (7 of 11) (supplemental Fig. 4, available at www.jneurosci. org as supplemental material). None of these putative O-LM interneurons expressed a detectable tail current.

We next examined whether GluR5-containing KARs contribute substantially to the evoked EPSCs on SO interneurons. We were unable to detect any significant effect of UBP 302 on the cumulative charge transfer for eEPSCs on SO interneurons, again in marked contrast to what we found on SR/SLM interneurons (SR/SLM, $n=9$; SO, $n=11$ ) (Fig. $7 D, E)$. Subdivision of SO interneurons into putative O-LM and non-O-LM also did not reveal a significant effect of UBP 302 in either set of cells $(1 \pm 1 \%$ in non-OLM cells, $n=4 ; 6 \pm 10 \%$ in O-LM cells, $n=7 ; p>0.3$ ). These results indicate that GluR5 is absent from synapses onto $\mathrm{SO}$ interneurons.

One possible explanation for this finding is that $\mathrm{SO}$ interneurons might not express GluR5. To assess the contribution of GluR5 to KARs on SO interneurons, we examined the effect of UBP 302 on currents elicited by domoate $(120 \pm 34 \mathrm{pA} ; n=3)$ and kainate $(105 \pm 52 \mathrm{pA} ; n=4)$ (supplemental Fig. 2, available at www.jneurosci.org as supplemental material). On average, UBP 302 was substantially more effective on currents elicited by these nonselective agonists in SO interneurons than in SR/SLM interneurons (SO, $57 \pm 14 \%$ inhibition; SR/SLM, $18 \pm 6 \%$ inhibition) (Fig. 7F) (supplemental Fig. 2, available at www. jneurosci.org as supplemental material). Rapid application of ATPA also elicited a current that was almost entirely blocked by UBP $302\left(I_{\text {ATPA }}, 19 \pm 3\right.$ pA; block by UBP 302, $\left.80 \pm 7 \% ; n=4\right)$ (Fig. $7 G$ ). Thus, GluR5-containing KARs are present on $\mathrm{SO}$ interneurons.

These results suggest that GluR5 is selectively localized to synapses onto SR/SLM interneurons but not SO interneurons, con- 
firming that the properties of KARs differ across different classes of interneuron. We reasoned that the large and rapid spontaneous KAR EPSCs found in previous studies of SO interneurons were likely attributable to KARs that lack the GluR5 subunit, which would not be sensitive to UBP 302 . To address this possibility, we examined whether a population of sEPSCs could be isolated in the presence of $50 \mu \mathrm{M}$ GYKI 53655. Surprisingly, however, we were unable to detect any GYKI 53655-resistant sEPSCs under these conditions $(n=13)$ (Fig. $7 H$ ).

To address the possibility that GluR7 might confer a higher GYKI 53655 sensitivity to KARs on SO interneurons, we repeated these experiments using $10 \mu \mathrm{M}$ GYKI 53655. This dose should strongly block AMPARs ( $90 \%$ inhibition) with only modest effects on GluR7-containing KARs ( $25 \%$ inhibition) (Perrais et al., 2008). Even under these conditions, GYKI 53655 led to an almost complete inhibition of sEPSCs ( $97 \pm 3 \%$ reduction in frequency; $n=3$ ) (supplemental Fig. 5, available at www.jneurosci.org as supplemental material). The rare remaining events in $10 \mu \mathrm{M}$

GYKI 53655 may be attributable to GluR7-containing KARs. However, we caution that we cannot exclude the alternative that they could be AMPAR-mediated EPSCs that were still within our limits of resolution during the strong, but incomplete, blockade by this concentration of GYKI 53655. In either case, we conclude that the contribution of postsynaptic KARs to the EPSC is minimal in SO interneurons and clearly distinct from the role of KARs in generating the slow EPSC in SR/SLM interneurons.

Thus, our findings do support the idea that the synaptic expression of KARs is different for SR/SLM interneurons and SO interneurons; however, this does not completely explain the discrepancy between the properties of synaptic KARs in SR/SLM interneurons that we have reported here and the properties of synaptic KARs in SO interneurons that have been presented in previous reports (Cossart et al., 2002; Goldin et al., 2007), because we did not observe the sEPSCs described in those reports.

The reason for the difference between our own findings and those of Cossart and colleagues is unclear. Even miniature KAR EPSCs reported by Cossart and colleagues were frequent $(\sim 2 \mathrm{~Hz}$ on average) and large $(\sim 10 \mathrm{pA}$ on average), so we should have been able to easily detect these events if they were present in our recordings. Similarly, we would not expect the size or frequency of miniature EPSCs to drop below our limit of resolution attributable to any of the minor experimental variables that often vary between laboratories. It may still be the case that we inadvertently recorded from a distinct subset of SO interneurons from those examined by Cossart and colleagues; however, we think this is unlikely, because a significant fraction of the cells in their studies were O-LM interneurons. These interneurons express unusual physiological characteristics, most notably a pronounced shortterm facilitation (Losonczy et al., 2002; Wierenga and Wadman, 2003; Pouille and Scanziani, 2004), and this was readily observed in many of our recordings of SO interneurons.

\section{Discussion}

In this study, we identified several parameters that specify the functions of KARs on hippocampal interneurons in area CA1. These interneurons express two distinct KAR subtypes: those that contain the GluR5 subunit and those that lack it. Although GluR5-lacking KARs generate most of the current in response to the exogenous agonists kainate and domoate, GluR5-containing KARs are the major KAR subtype activated during synaptic transmission onto SR/SLM interneurons. The KAR EPSC on these cells is small and slow, and to our surprise we found a component of the AMPAR EPSC that was similarly small and slow. However, several lines of evidence suggest that the slow kinetics of the KAR EPSC do not reflect glutamate spillover onto extrasynaptic KARs. Moreover, KARs do not contribute a resolvable tail component to sEPSCs identified by the presence of a conventional rapid AMPAR component, indicating that the synapses that generate these large, rapid sEPSCs cannot account for the KAR currents in the evoked EPSC. In contrast to these findings in SR/SLM interneurons, we were unable to demonstrate any substantial contribution of postsynaptic KARs to the EPSC in SO interneurons.

\section{Subunit composition regulates the synaptic localization of KARs}

Our results demonstrate the existence of two distinct subtypes of KARs on hippocampal SR/SLM interneurons that differ in their subunit composition. GluR5-containing KARs are targeted to synapses and generate a small, slow EPSC. GluR5lacking KARs are excluded from the area surrounding the synapse, and their function remains unclear. One possibility is that they regulate excitability at the soma via metabotropic effects on the afterhyperpolarization (Melyan et al., 2002; Fisahn et al., 2005).

UBP 302 was far more effective at inhibiting synaptic currents than it was on currents evoked by kainate or domoate, so 

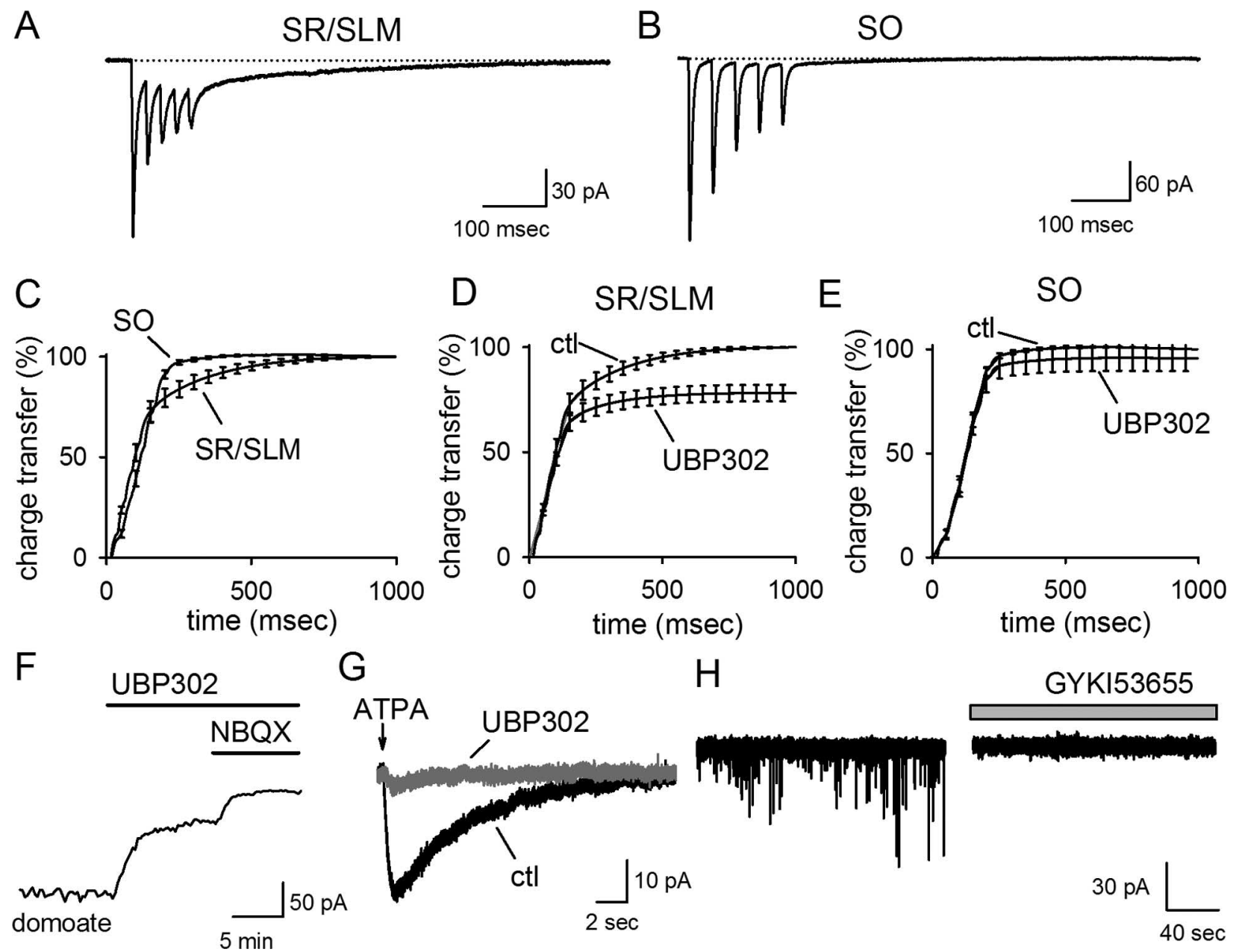

$\mathrm{H}$

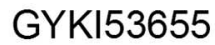

Figure 7. GluR5 KARs are excluded from the synapse at stratum oriens interneurons. A, Averaged eEPSCs recorded from an SR/SLM interneuron have a distinct, slowly decaying tail current. $\boldsymbol{B}$, Averaged eEPSCs recorded in SO have notably smaller tail currents, when detected at all. C, The slow tail current contributes significantly to the charge transfer of the EPSCS recorded from SR/SLM cells but not for EPSCS recorded from SO interneurons. D, In SR/SLM cells, the late, slow component of the tail is significantly blocked by UBP 302 . Here and in $E$, the total charge transfer during the EPSCs are normalized with respect to the total charge transfer in control conditions (ctl); thus, the fact that the charge transfer in the presence of UBP 302 reaches an asymptote at significantly $<100 \%$ in SR/SLM interneurons indicates that the total charge transfer is significantly reduced by UBP 302 in these cells. $E$, UBP 302 has no significant effect on the cumulative charge transfer of eEPSCs in SO interneurons. UBP 302 substantially blocked currents induced by nonselective KAR agonists, as shown by the effect of UBP 302 on currents elicited by $50 \mathrm{~nm}$ domoate $(\boldsymbol{F})$ or by the GluR5-selective agonist ATPA (G). $\boldsymbol{H}$, All resolvable sEPSCs were blocked by $50 \mu \mathrm{m}$ GYKI 53655 in 50 interneurons.

the current evoked by nonselective agonists is dominated by GluR5-lacking KARs that are distinct from the GluR5containing KARs at the synapse. This dominance of GluR5lacking KARs in response to exogenous agonists compared with synaptic glutamate is unlikely to be attributable to different subunit preferences for the different agonists, because none of them have a substantial preference for GluR6 over GluR5 (supplemental Table 1, available at www.jneurosci.org as supplemental material). It is also unlikely that the difference stems from activation of distinct subunits within heteromeric receptors, because UBP 302 can fully antagonize currents elicited in GluR5-containing heteromers (Alt et al., 2004; More et al., 2004).

To our knowledge, these results are the first demonstration that native KARs are differentially incorporated into the postsynaptic site or excluded from it based on their subunit composition. Subunit-dependent synaptic targeting of AMPARs is thought to underlie long-term plasticity (Lüscher et al., 2000; Bredt and Nicoll, 2003) and occurs in interneurons (Tóth and McBain, 1998). It seems likely that similar mechanisms are involved in targeting of KARs. Consistent with this, the C-terminal sequences of both GluR6 and splice variants of GluR5 contain PDZ (postsynaptic density-95/Discs large/zona occludens-1)-binding motifs and can interact with scaffolding proteins (Garcia et al., 1998; Hirbec et al., 2003). However, it remains unclear whether glutamate receptor trafficking is similar in interneurons and pyramidal cells, because these cell types also express different AMPAR subunits (Geiger et al., 1995).

AMPARs are more effectively recruited by glutamate spillover than KARs

Both AMPARs and KARs can support a slow tail current that lasts for hundreds of milliseconds after the peak of the EPSC. This led us to carefully evaluate the possibility that the slow EPSC is generated by the extrasynaptic spillover of glutamate, sensed by both receptor subtypes. Attempts to elicit spillover by brief trains did not facilitate either the KAR EPSC or the AMPAR EPSC; blocking glutamate uptake did not resolvably enhance the KAR EPSC but recruited a substantial spillovermediated AMPAR EPSC. The finding that glutamate transporters so profoundly limit the activation of AMPARs but not KARs during synaptic glutamate release is surprising, because 
it suggests that KARs are located opposite the glutamate release site more precisely than AMPARs. Thus, the slow kinetics of the KAR EPSC likely reflect intrinsic properties of native receptors that are determined by KAR subunit composition (Contractor et al., 2000), interactions with accessory proteins (Garcia et al., 1998), or cytosolic messengers (Swanson and Heinemann, 1998).

The results with TBOA demonstrate that a slow spillovermediated AMPAR EPSC can be recruited by blocking glutamate uptake. This effect is useful in the current context as a control, indicating that TBOA can elicit spillover although it has no effect on the KAR EPSC. More generally, the effect of TBOA on AMPARs at this synapse is massive compared with other effects of spillover onto AMPARs (Arnth-Jensen et al., 2002; Chen and Diamond, 2002; Diamond, 2002; DiGregorio et al., 2002; Takayasu et al., 2004; DeVries et al., 2006). The recruitment of a slow AMPAR EPSC by TBOA lends some credence to the idea that the slow AMPAR component during the evoked EPSC might be mediated by spillover even during single stimuli under normal conditions.

However, our data are not immediately compatible with this idea: if single stimuli were sufficient to overwhelm uptake and elicit spillover lasting for hundreds of milliseconds, it would also surely be the case that this spillover could be facilitated during brief high-frequency trains, which should more effectively overwhelm uptake than single stimuli. We did not observe a facilitation of the tail current during trains, nor was there an activitydependent change in the relative contribution of AMPARs to the EPSC. Thus, the mechanisms underlying the slow AMPAR tail current remain unclear. One possibility is that the slow AMPAR component of the EPSC when uptake is intact reflects activation of a distinct subset of synaptic AMPARs with unusual properties, possibly conferred by accessory proteins (Cho et al., 2007; Milstein et al., 2007).

\section{KAR expression at synapses underlying the rapid AMPAR sEPSCs is negligible}

The absence of a resolvable tail current in averaged sEPSCs from SR/SLM interneurons indicates that at least some of the synapses that mediate the fast component of the evoked EPSC have AMPARs without a substantial complement of KARs. For the same reason, the AMPARs that contribute to the tail current of the evoked EPSC are also unlikely to be present at these synapses. Because the KAR component of the evoked EPSC is not a result of spillover, we infer that a separate population of synapses must have KARs without a substantial complement of AMPARs. We were unable to directly resolve sEPSCs with these properties; however, given the small size of the KAR EPSC even when evoked by extracellular stimulation, we would expect that these events are too small for us to detect. An alternate explanation is that the KAR-enriched synapses might have an exceptionally low spontaneous release rate, so that they simply do not generate sEPSCs. In either case, our results suggest that different synapses onto SR/ SLM interneurons activate different receptors with distinct kinetics and may mediate distinct functions; inputs generating the fast AMPAR EPSC would transmit afferent spike timing, whereas inputs generating the slow AMPAR and/or KAR EPSCs would transmit afferent spike rates (König et al., 1996; Frerking and Ohliger-Frerking, 2002). One possible explanation for these kinetically distinct synapses is that they may correlate with distinct afferent populations, because SR/SLM interneurons receive inputs from the entorhinal cortex in addition to CA3 pyramidal cells (Somogyi and Klausberger, 2005).

\section{GluR5-containing KARs are a substantial contributor to the EPSC on SR/SLM interneurons but not SO interneurons}

In contrast to our results in SR/SLM interneurons, most SO interneurons had little or no tail current in the evoked EPSC, and we were unable to detect any effect of UBP 302 on the eEPSCs in these cells. Thus, the slow KAR EPSC mediated by GluR5-containing KARs in SR/SLM interneurons is differentially expressed across distinct subsets of interneurons. GluR5-containing KARs on SO interneurons were activated by exogenous agonists, consistent with previous reports (Yang et al., 2006, 2007), so the absence of synaptic GluR5containing KARs in SO interneurons is not attributable to a lack of GluR5.

Is there a functional significance to the selective expression of the slow KAR EPSC on SR/SLM interneurons but not SO interneurons? There are a number of differences between SR/SLM interneurons and SO interneurons (supplemental Note 1, available at www.jneurosci.org as supplemental material); a notable distinction is that SO interneurons are the major source of feedback inhibition, whereas SR/SLM interneurons are major contributors to feedforward inhibition (Freund and Buzsaki, 1996; McBain, 2000; McBain and Fisahn, 2001). Research on feedforward inhibition has focused on temporal precision and synchrony (Pouille and Scanziani, 2001; Assisi et al., 2007; Bartos et al., 2007; Mann and Paulsen, 2007), which is likely mediated by fast AMPAR inputs on SR/SLM interneurons. Synapses that express KARs would more likely be an activity-dependent mechanism for slow, reliable changes in the background membrane potential.

In summary, the synaptic expression of KARs in hippocampal interneurons is finely tuned, through subunit-dependent localization of KARs to a subset of synapses on SR/SLM interneurons but not SO interneurons. The precision of KAR targeting and the unusual kinetics of the KAR EPSC suggest that these receptors play a specific and distinct role in signal processing during the transfer of information through the hippocampal circuit.

\section{References}

Alt A, Weiss B, Ogden AM, Knauss JL, Oler J, Ho K, Large TH, Bleakman D (2004) Pharmacological characterization of glutamatergic agonists and antagonists at recombinant human homomeric and heteromeric kainate receptors in vitro. Neuropharmacology 46:793-806.

Arnth-Jensen N, Jabaudon D, Scanziani M (2002) Cooperation between independent hippocampal synapses is controlled by glutamate uptake. Nat Neurosci 5:325-331.

Assisi C, Stopfer M, Laurent G, Bazhenov M (2007) Adaptive regulation of sparseness by feedforward inhibition. Nat Neurosci 10:1176-1184.

Baraban SC, Tallent MK (2004) Interneuron Diversity series: Interneuronal neuropeptides-endogenous regulators of neuronal excitability. Trends Neurosci 27:135-142.

Barberis A, Sachidhanandam S, Mulle C (2008) GluR6/KA2 kainate receptors mediate slow-deactivating currents. J Neurosci 28:6402-6406.

Bartos M, Vida I, Jonas P (2007) Synaptic mechanisms of synchronized gamma oscillations in inhibitory interneuron networks. Nat Rev Neurosci 8:45-56.

Bettler B, Mulle C (1995) Review: neurotransmitter receptors. II. AMPA and kainate receptors. Neuropharmacology 34:123-139.

Bredt DS, Nicoll RA (2003) AMPA receptor trafficking at excitatory synapses. Neuron 40:361-379.

Bureau I, Bischoff S, Heinemann SF, Mulle C (1999) Kainate receptormediated responses in the CA1 field of wild-type and GluR6-deficient mice. J Neurosci 19:653-663.

Bureau I, Dieudonne S, Coussen F, Mulle C (2000) Kainate receptormediated synaptic currents in cerebellar Golgi cells are not shaped by diffusion of glutamate. Proc Natl Acad Sci U S A 97:6838-6843.

Castillo PE, Malenka RC, Nicoll RA (1997) Kainate receptors mediate a 
slow postsynaptic current in hippocampal CA3 neurons. Nature 388:182-186.

Chen S, Diamond JS (2002) Synaptically released glutamate activates extrasynaptic NMDA receptors on cells in the ganglion cell layer of rat retina. J Neurosci 22:2165-2173.

Cho CH, St-Gelais F, Zhang W, Tomita S, Howe JR (2007) Two families of TARP isoforms that have distinct effects on the kinetic properties of AMPA receptors and synaptic currents. Neuron 55:890-904.

Christensen JK, Paternain AV, Selak S, Ahring PK, Lerma J (2004) A mosaic of functional kainate receptors in hippocampal interneurons. J Neurosci 24:8986-8993.

Christie JM, Jahr CE (2006) Multivesicular release at Schaffer collateralCA1 hippocampal synapses. J Neurosci 26:210-216.

Contractor A, Swanson GT, Sailer A, O'Gorman S, Heinemann SF (2000) Identification of the kainate receptor subunits underlying modulation of excitatory synaptic transmission in the CA3 region of the hippocampus. J Neurosci 20:8269-8278.

Contractor A, Sailer AW, Darstein M, Maron C, Xu J, Swanson GT, Heinemann SF (2003) Loss of kainate receptor-mediated heterosynaptic facilitation of mossy-fiber synapses in $\mathrm{KA} 2^{-1-}$ mice. J Neurosci 23:422-429.

Cossart R, Esclapez M, Hirsch JC, Bernard C, Ben-Ari Y (1998) GluR5 kainate receptor activation in interneurons increases tonic inhibition of pyramidal cells. Nat Neurosci 1:470-478.

Cossart R, Epsztein J, Tyzio R, Becq H, Hirsch J, Ben-Ari Y, Crépel V (2002) Quantal release of glutamate generates pure kainate and mixed AMPA/ kainate EPSCs in hippocampal neurons. Neuron 35:147-159.

DeVries SH (2000) Bipolar cells use kainate and AMPA receptors to filter visual information into separate channels. Neuron 28:847-856.

DeVries SH, Schwartz EA (1999) Kainate receptors mediate synaptic transmission between cones and "Off" bipolar cells in a mammalian retina. Nature 397:157-160.

DeVries SH, Li W, Saszik S (2006) Parallel processing in two transmitter microenvironments at the cone photoreceptor synapse. Neuron 50:735-748.

Diamond JS (2002) A broad view of glutamate spillover. Nat Neurosci 5:291-292.

DiGregorio DA, Nusser Z, Silver RA (2002) Spillover of glutamate onto synaptic AMPA receptors enhances fast transmission at a cerebellar synapse. Neuron 35:521-533.

Eder M, Becker K, Rammes G, Schierloh A, Azad SC, Zieglgänsberger W, Dodt HU (2003) Distribution and properties of functional postsynaptic kainate receptors on neocortical layer V pyramidal neurons. J Neurosci 23:6660-6670.

Fisahn A, Contractor A, Traub RD, Buhl EH, Heinemann SF, McBain CJ (2004) Distinct roles for the kainate receptor subunits GluR5 and GluR6 in kainate-induced hippocampal gamma oscillations. J Neurosci 24:9658-9668.

Fisahn A, Heinemann SF, McBain CJ (2005) The kainate receptor subunit GluR6 mediates metabotropic regulation of the slow and medium AHP currents in mouse hippocampal neurones. J Physiol 562:199-203.

Frerking M, Nicoll RA (2000) Synaptic kainate receptors. Curr Opin Neurobiol 10:342-351.

Frerking M, Ohliger-Frerking P (2002) AMPA receptors and kainate receptors encode different features of afferent activity. J Neurosci 22:7434-7443.

Frerking M, Malenka RC, Nicoll RA (1998) Synaptic activation of kainate receptors on hippocampal interneurons. Nat Neurosci 1:479-486.

Freund TF, Buzsáki G (1996) Interneurons of the hippocampus. Hippocampus 6:347-470.

Garcia EP, Mehta S, Blair LA, Wells DG, Shang J, Fukushima T, Fallon JR, Garner CC, Marshall J (1998) SAP90 binds and clusters kainate receptors causing incomplete desensitization. Neuron 21:727-739.

Geiger JR, Melcher T, Koh DS, Sakmann B, Seeburg PH, Jonas P, Monyer H (1995) Relative abundance of subunit mRNAs determines gating and $\mathrm{Ca}^{2+}$ permeability of AMPA receptors in principal neurons and interneurons in rat CNS. Neuron 15:193-204.

Goldin M, Epsztein J, Jorquera I, Represa A, Ben-Ari Y, Crépel V, Cossart $\mathrm{R}$ (2007) Synaptic kainate receptors tune oriens-lacunosum moleculare interneurons to operate at theta frequency. J Neurosci 27:9560-9572.

Hirbec H, Francis JC, Lauri SE, Braithwaite SP, Coussen F, Mulle C, Dev KK,
Coutinho V, Meyer G, Isaac JT, Collingridge GL, Henley JM (2003) Rapid and differential regulation of AMPA and kainate receptors at hippocampal mossy fibre synapses by PICK1 and GRIP. Neuron 37:625-638.

Huettner JE (2003) Kainate receptors and synaptic transmission. Prog Neurobiol 70:387-407.

Khalilov I, Hirsch J, Cossart R, Ben-Ari Y (2002) Paradoxical anti-epileptic effects of a GluR5 agonist of kainate receptors. J Neurophysiol $88: 523-527$.

Kidd FL, Isaac JT (1999) Developmental and activity-dependent regulation of kainate receptors at thalamocortical synapses. Nature 400:569-573.

Kidd FL, Isaac JT (2001) Kinetics and activation of postsynaptic kainate receptors at thalamocortical synapses: role of glutamate clearance. J Neurophysiol 86:1139-1148.

König P, Engel AK, Singer W (1996) Integrator or coincidence detector? The role of the cortical neuron revisited. Trends Neurosci 19:130-137.

Lein ES, Hawrylycz MJ, Ao N, Ayres M, Bensinger A, Bernard A, Boe AF, Boguski MS, Brockway KS, Byrnes EJ, Chen L, Chen L, Chen TM, Chin MC, Chong J, Crook BE, Czaplinska A, Dang CN, Datta S, Dee NR, et al. (2007) Genome-wide atlas of gene expression in the adult mouse brain. Nature 445:168-176.

Lerma J (2006) Kainate receptor physiology. Curr Opin Pharmacol 6:89-97.

Lerma J, Paternain AV, Rodríguez-Moreno A, López-García JC (2001) Molecular physiology of kainate receptors. Physiol Rev 81:971-998.

Li P, Wilding TJ, Kim SJ, Calejesan AA, Huettner JE, Zhuo M (1999) Kainate-receptor-mediated sensory synaptic transmission in mammalian spinal cord. Nature 397:161-164.

Losonczy A, Zhang L, Shigemoto R, Somogyi P, Nusser Z (2002) Cell type dependence and variability in the short-term plasticity of EPSCs in identified mouse hippocampal interneurones. J Physiol 542:193-210.

Lüscher C, Nicoll RA, Malenka RC, Muller D (2000) Synaptic plasticity and dynamic modulation of the postsynaptic membrane. Nat Neurosci 3:545-550.

Maingret F, Lauri SE, Taira T, Isaac JT (2005) Profound regulation of neonatal CA1 rat hippocampal GABAergic transmission by functionally distinct kainate receptor populations. J Physiol 567:131-142.

Mann EO, Paulsen O (2007) Role of GABAergic inhibition in hippocampal network oscillations. Trends Neurosci 30:343-349.

McBain CJ (2000) Multiple forms of feedback inhibition by str. oriens inhibitory interneurons? J Physiol 524:2.

McBain CJ, Fisahn A (2001) Interneurons unbound. Nat Rev Neurosci 2:11-23.

Melyan Z, Wheal HV, Lancaster B (2002) Metabotropic-mediated kainate receptor regulation of IsAHP and excitability in pyramidal cells. Neuron 34:107-114.

Milstein AD, Zhou W, Karimzadegan S, Bredt DS, Nicoll RA (2007) TARP subtypes differentially and dose-dependently control synaptic AMPA receptor gating. Neuron 55:905-918.

More JC, Nistico R, Dolman NP, Clarke VR, Alt AJ, Ogden AM, Buelens FP, Troop HM, Kelland EE, Pilato F, Bleakman D, Bortolotto ZA, Collingridge GL, Jane DE (2004) Characterisation of UBP296: a novel, potent and selective kainate receptor antagonist. Neuropharmacology $47: 46-64$.

Mulle C, Sailer A, Swanson GT, Brana C, O'Gorman S, Bettler B, Heinemann SF (2000) Subunit composition of kainate receptors in hippocampal interneurons. Neuron 28:475-484.

Paternain AV, Rodríguez-Moreno A, Villarroel A, Lerma J (1998) Activation and desensitization properties of native and recombinant kainate receptors. Neuropharmacology 37:1249-1259.

Paternain AV, Herrera MT, Nieto MA, Lerma J (2000) GluR5 and GluR6 kainate receptor subunits coexist in hippocampal neurons and coassemble to form functional receptors. J Neurosci 20:196-205.

Perrais D, Pinheiro PS, Jane DE, Mulle C (2008) Antagonism of recombinant and native GluK3-containing kainate receptors. Neuropharmacology. Advance online publication. Retrieved Aug. 31, 2008. doi:10.1016/j.neuropharm.2008.08.002.

Pinheiro P, Mulle C (2006) Kainate receptors. Cell Tissue Res 326:457-482.

Pouille F, Scanziani M (2001) Enforcement of temporal fidelity in pyramidal cells by somatic feed-forward inhibition. Science 293:1159-1163. 
Pouille F, Scanziani M (2004) Routing of spike series by dynamic circuits in the hippocampus. Nature 429:717-723.

Somogyi P, Klausberger T (2005) Defined types of cortical interneurone structure space and spike timing in the hippocampus. J Physiol 562:9-26.

Sun HY, Dobrunz LE (2006) Presynaptic kainate receptor activation is a novel mechanism for target cell-specific short-term facilitation at Schaffer collateral synapses. J Neurosci 26:10796-10807.

Swanson GT, Heinemann SF (1998) Heterogeneity of homomeric GluR5 kainate receptor desensitization expressed in HEK293 cells. J Physiol 513:639-646.

Takayasu Y, Iino M, Ozawa S (2004) Roles of glutamate transporters in shaping excitatory synaptic currents in cerebellar Purkinje cells. Eur J Neurosci 19:1285-1295.
Tong G, Jahr CE (1994) Multivesicular release from excitatory synapses of cultured hippocampal neurons. Neuron 12:51-59.

Tóth K, McBain CJ (1998) Afferent-specific innervation of two distinct AMPA receptor subtypes on single hippocampal interneurons. Nat Neurosci 1:572-578.

Vignes M, Collingridge GL (1997) The synaptic activation of kainate receptors. Nature 388:179-182.

Wierenga CJ, Wadman WJ (2003) Excitatory inputs to CA1 interneurons show selective synaptic dynamics. J Neurophysiol 90:811-821.

Yang EJ, Harris AZ, Pettit DL (2006) Variable kainate receptor distributions of oriens interneurons. J Neurophysiol 96:1683-1689.

Yang EJ, Harris AZ, Pettit DL (2007) Synaptic kainate currents reset interneuron firing phase. J Physiol 578:259-273. 